\title{
General Adaptive Composite Score
}

National Cancer Institute

\section{Source}

National Cancer Institute. General Adaptive Composite Score. NCI Thesaurus. Code C121204.

An overall score of the Adaptive Behavior Assessment System that consists of the three domains of conceptual, social, and practical. 